clozapine in such patients may be unjustified as the patients may be denied proper treatment.

Ames, D., Wirshing, W. C., Baker, R. W., et ol (1996)

Predictive value of eosinophilia for neutropenia during clozapine treatment. Journol of Clinicol Psychiatry, 57, 579-581.

Amital, D. Gross, R., Amital, H., et al (1997)

Coexistence of eosinophilia and agranulocytosis in a clozapine-treated patient (letter). British fournal of Psychiatry. 170. 194

Bailey, P. (1997) Clozapine treatment, eosinophilia and agranulocytosis (letter). British journal of Psychiatry, 171, 90

Banov, M., Tohon, M. L. Friedbere, J. (1993) High risk of eosinophilia in women treated with clozapine. Journal of Clinical Psychiotry, 54, 466-469.

Galletiey, C., Wilson, D. \& McEwen, S. (1996) Eosinophilia associated with decreasing neutrophil count in a clozapinetreated patient (letter). Journal of Clinical Psychiotry, 57. $40-41$

Gerlach, J., Jorgensen, E. O. \& Peacock, L. (1989) Long term experience with clozapine in Denmark: research and clinical practice. Psychophormocology. 99. $592-593$

Hummer, M., Spernerunterwezer, B., Kemmler, G., et of (1996) Does eosinophilia predict clozapine-induced neutropenia? Psychophormacology, 124, 201-204

M. D. Adityanjee, V. Chowdary Jampala

Psychiatry Service, Veterans Affairs Medical Center. 4100W. Third Street, Dayton, OH 45434, USA

Madan S. Mohan Department of Psychiatry. Wright State University School of Medicine

\section{Establishing cost-effectiveness of antipsychotic drugs}

Sir: In commenting on the work of Aitchison \& Kerwin (1997), Robert \& Kennedy (1997) make a plea for more long-term, large-sample, randomised, controlled trials evaluating the healtheconomics of antipsychotic prescribing. While I agree that such studies would indeed be useful, I feel that open, mirrorimage studies like that of Aitchison \& Kerwin have greater practical value. As a manager of a trust drugs budget, I need to know the cost-effectiveness of drugs used under normal clinical circumstances in an environment similar to, or the same as, my trust. Indeed, purchasers of health care often demand parochial healtheconomic trials before they will consider funding, showing only a passing interest in large-scale multi-centre, randomised controlled trials, despite their scientific rigour. This is because, with all their inclusions, exclusions and intensive observations, these studies only indirectly reflect clinical practice.
Let us conduct more long-term, controlled studies, but let us also note carefully the results of open, uncontrolled trials which better reflect the real world.

Aitchison, K. J. \& Kerwin R.W. (1997) Cost-effectiveness of clozapine: a UK clinic-based study. British journal of Psychiatry, 171, 125-130.

Robert, G. \& Kennedy, P. (1997) Establishing costeffectiveness of atypical neuroleptics. British journal of Psychiotry, 17I, 103-104.

David M. Taylor Bethlem and Maudsley NHS Trust, Maudsley Hospital, Denmark Hill, London SE5 8AZ

Sir: In their excellent article, Robert \& Kennedy (1997) reference two reviews in the Cochrane Library (bttp://archie.cochrane.co.uk,info/) (Adams \& Soares, 1997). These are now completed. One, on clozapine, has been available for some time and has been updated every three months since publication (Wahlbeck et al, 1997). This will soon contain what data are available from recent trials that have, at last, looked at economic outcomes. The review on risperidone is also complete (Kennedy $e t$ $a l, 1997)$ and the next version of the Cochrane Library will contain this as well. What few data there are on cost-effectiveness will be presented. A similar review on olanzapine is starting. Every attempt is made to keep the systematically conducted reviews on the Cochrane Library up-todate. Abstracts of completed reviews and titles of those underway are readily available (http:/larchie.cochrane.co.uk/infolabstracts/abidx.htm\#G06@).

Adams, C. E., Soares, K. (1997) The Cochrane Collaboration and the process of systematic reviewing. Advances in Psychiatric Treatment, 3. 240-246.

Kennedy, E., Song, F., Hunter, R., et al (1997) Risperidone for schizophrenia. The Cochrane Library (CD-ROM). The Cochrane Collaboration; Issue 3. Oxford: Update Software.

Robert, G. \& Kennedy, P. (1997) Establishing costeffectiveness of atypical neuroleptics. British journal of Psychiatry. 171, 103-104.

Wahlbeck, K., Cheine, M., Essall, M. A., ot al (1997) Clozapine vs 'typical' neuroleptic medication for schizophrenia. The Cochrane Library (CD-ROM). The Cochrane Collaboration; Issue 3. Oxford: Update Software.

Clive E. Adams Summertown Pavilion, Middle Way, Oxford OX2 7LG

\section{Disorders of the mother-infant relationship}

Sir: Professor Kumar's (1997) questionnaire study of 44 women with disorders of maternal 'bonding' has confirmed the duration of the disorder and the importance of parturition stress. I am surprised that he failed to find a link with unwanted pregnancy and disorders of prepartum affiliation because these are supported by other studies (Arbeit, 1975). He seems not to have considered the child's contribution to this relationship.

My most serious concern, however, is his remark about treatment. There is no discussion of treatment in the text, but the table of "clinical implications" states that "there are as yet no specific therapies". The word 'specific' presumably means therapies tailor-made to address this particular problem, not any other. The principles of treatment were set out in my earlier account (Brockington, 1996, pp. 347-360): they include specific elements directed at mother-infant interaction. Professor Kumar's negative remark about therapy may give a misleading impression to sufferers and their therapists. These are severe disorders, they are common and neglected, but, provided the disordered mother-infant relationship is identified, and not subsumed under a label such as 'postnatal depression', the treatment response is excellent.

Arbeit, S. A. (1975) A Study of Women During their First Pregnancy. PhD Thesis, Yale University.

Brockington, I. F. (1996) Motherhood and Mental Health. Oxford: Oxford University Press.

Kumar, R. C. (1997) "Anybody's child": severe disorders of mother-to-infant bonding. British Journal of Psychiotry, I7I $175-181$.

I. F. Brockington Department of Psychiatry, The University of Birmingham, Queen Elizabeth Psychiatric Hospital, Mindelsohn Way, Birmingham BI5 2QZ

\section{Neuropsychological and imaging differences in dementia with Lewy bodies and Alzheimer's disease}

Sir: We agree with the recent editorial by Miller (1997) that recognition of the characteristic features of the different dementias has become increasingly important, especially in view of new treatment possibilities. We are surprised, however, 